\title{
THE FIRST SUBSTANTIATED RECORD OF THE YELLOWBAR ANGELFISH, POMACANTHUS MACULOSUS (ACTINOPTERYGII: PERCIFORMES: POMACANTHIDAE) IN THE MEDITERRANEAN
}

\author{
Pierre SALAMEH ${ }^{1}$, Oren SONIN ${ }^{1}$, Dor EDELIST ${ }^{1,2}$, and Daniel GOLANI ${ }^{3 *}$ \\ ${ }^{1}$ Department of Fisheries Ministry of Agriculture, P.O. Box 1213 Kiryat Haim, 26105, Israel \\ ${ }^{2}$ The Leon Recanati Institute for Maritime Studies, University of Haifa, Haifa 31905, Israel \\ ${ }^{3}$ National Natural History Collection and Department of Ecology, Evolution and Behaviour, \\ The Hebrew University of Jerusalem, 91994 Jerusalem, Israel
}

Salameh P., Sonin O., Edelist D., Golani D. 2012. The first substantiated record of the yellowbar angelfish, Pomacanthus maculosus (Actinopterygii: Perciformes: Pomacanthidae) in the Mediterranean. Acta Ichthyol. Piscat. 42 (1): 73-74.

\begin{abstract}
A specimen of the Red Sea and western Indian Ocean Pomacanthus maculosus was collected from the Mediterranean coast of Israel. This record constitutes the first substantiated** record from this region. In the case of a previous record of this species from Lebanon, no specimen was preserved. These two records, in addition to a video clip, an underwater photograph and several observations of this species from Israel indicates that P. maculosus has established a population in the Levant.
\end{abstract}

Keywords: Pomacanthus maculosus, eastern Mediterranean, Lessepsian migration, population establishment

On 24 November 2009 a local diver, Mr. Alon Neuberger, photographed a 58 -s video clip of a specimen of Pomacanthus maculosus (Forsskål in Niebuhr, 1775) at a depth of $10 \mathrm{~m}$ near Givat Olga, ca. $40 \mathrm{~km}$ north of Tel Aviv. A week later, the diver returned to the same site but was unable to find the fish. The video clip was presented to the authors but, due to its uneven quality, we decided to refrain from publishing this record and decided to wait until a specimen was collected.

In January 2010 Bariche (2010) reported that on 8 September 2009 a specimen of $P$. maculosus was speared at a depth of $25 \mathrm{~m}$ south of Beirut and photographed. The specimen was consumed and therefore unfortunately was not preserved.

On 26 July 2011 a 279 mm (SL) (337 mm TL) specimen of Pomacanthus maculosus, weighing $1317.5 \mathrm{~g}$ (Fig. 1) was speared at a depth of $10 \mathrm{~m}$ near Tel Shiqmona $\left(32^{\circ} 49^{\prime} 27^{\prime \prime} \mathrm{N}, 34^{\circ} 56^{\prime} 49^{\prime \prime} \mathrm{E}\right)$ at the southern edge of Haifa Bay. The specimen was deposited in the Hebrew University Fish Collection (HUJ) and received the catalog number HUJ 20102. Since the Lebanese specimen was not preserved to enable further examination, the present record constitutes the first substantiated record of Pomacanthus maculosus from the Mediterranean.

Description of the specimen of Pomacanthus maculosus from Israel. Body deep (63.4\% of SL) and compressed. Small head $(25.3 \%$ of SL) with pointed small slightly oblique mouth, not reaching vertical line of eye. Bands of tightly-packed narrow depressible unicuspid teeth forming brush-like surface in both jaws. Six gill rakers on upper limb of first arch and 14 on lower limb. Upper profile of head slightly concave. Small eye (16.4\% of head length). Wide interorbital (37.2\% of head length). Posterior margin of operculum finely serrated with stout spine at angle (30.5\% of head length). Dorsal fin with 11 spines: first 6 spines with very deep notches; 20 rays: fourth and fifth distinctly elongated, ending in long filament measuring 53.8\% SL. Anal fin with three spines and 19 rays, fourth and fifth rays having filaments measuring $19.4 \%$ of SL. Caudal fin rounded with 16 rays. Pectoral fin with 18 rays. Pelvic fin with one spine and five rays: first ray distinctly elongated and filamentous, reaching back to anus. Body covered with ctenoid scales extending to head and on bases of median fins. Colour of fresh specimen (after being frozen for one month): Body bluishgrey with broad vertical yellow bar on body, slightly behind its centre. Black spots on posterior of upper posterior part of head. Caudal fin yellowish-grey.

Remarks. The distribution range of Pomacanthus maculosus includes the Red Sea and the Persian Gulf (known also as Arabian Gulf) to Mozambique (Randall 1983, 1995, Allen et al. 1998) and is usually found on coral and rocky substrata at depths down to $60 \mathrm{~m}$ (Lieske and Myers 2004). P. maculosus live singly or in pairs and

\footnotetext{
${ }^{*}$ Correspondence: Dr. Daniel Golani, National Natural History Collection and Department of Ecology, Evolution and Behaviour, The Hebrew University of Jerusalem, 91994 Jerusalem, Israel, phone: +972-2-6585872, fax: +973-2-6584741 e-mail: dgolani@cc.huji.ac.il [E-mails of other authors: pierres@moag.gov.il (Salameh); orens@moag.gov.il (Sonin),blackreef@gmail.com (Edelist)]

${ }^{* *}$ Defined by authors as based on a specimen deposited in a recognized museum.
} 


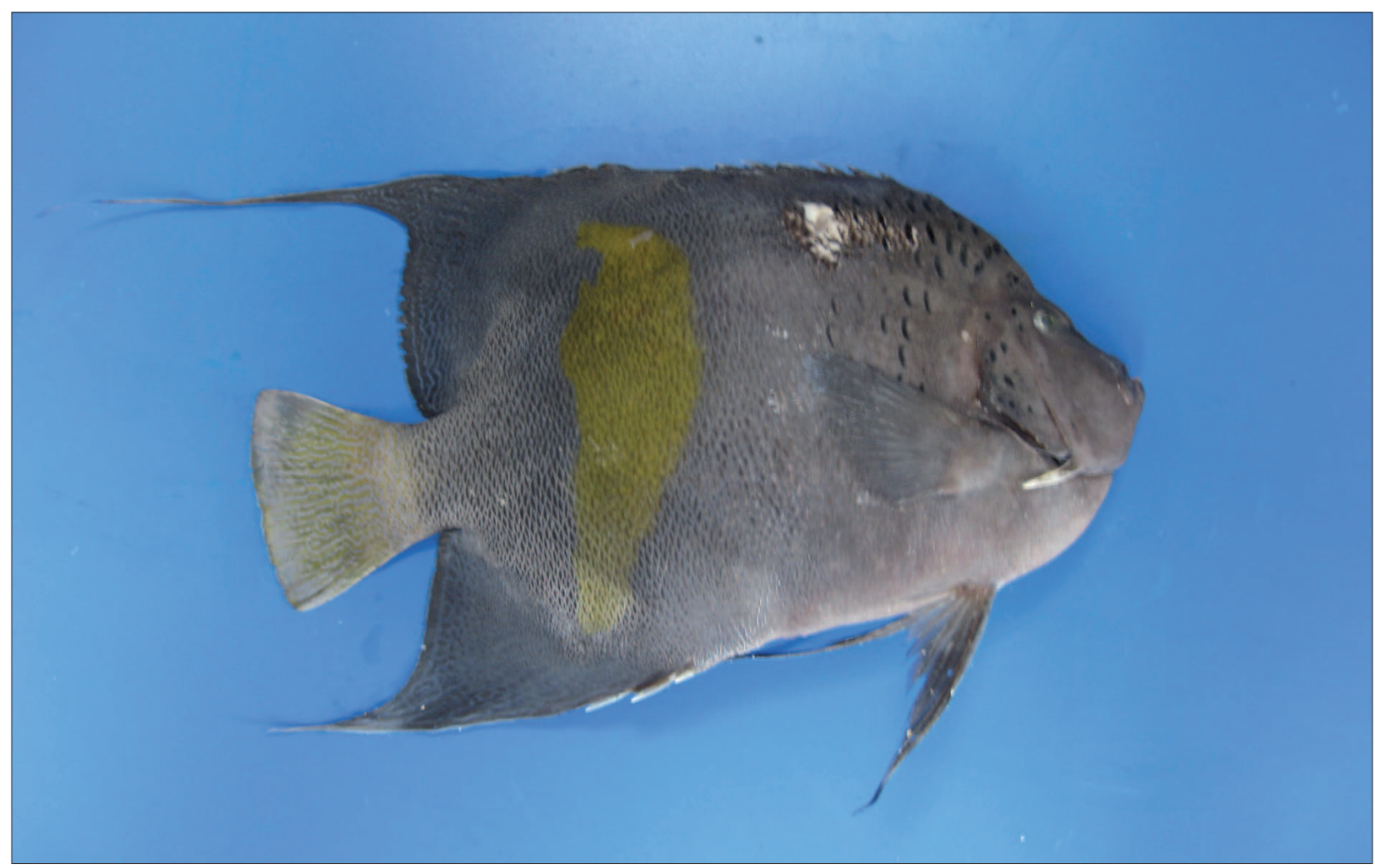

Fig. 1. Pomacanthus maculosus (279 mm SL) from the Mediterranean coast of Israel, (HUJ 20102)

feed on sponges and algae that they scrap with their brush-like teeth. Eggs and larvae are planktonic. The colour of young specimens (less than $10 \mathrm{~cm} \mathrm{TL}$ ) differs significantly from that of adults; in such juveniles, the bodies are dark blue to almost black with many narrow light blue and white vertical lines. According to Allen et al. (1998), there are some cases of P. maculosus hybridizing with the goldtail angelfish, P. chrysurus (Cuvier, 1831).

Pomacanthus maculosus evidently reached the Mediterranean via the Suez Canal (Lessepsian migrant). Bariche (2010) raised the possibility that the Lebanese specimen of Pomacanthus maculosus was merely a vagrant individual and suggested that it be considered an "unestablished alien". However, the collection of a specimen in Lebanon in autumn 2009, the present specimen, the video clip from Givat Olga, Israel and several observations reporting and photographing this species in Israel all indicate that $P$. maculosus is established in the eastern Levant.

\section{ACKNOWLEDGEMENTS}

We would like to thank Mr. Moshe Rouimi for collecting and providing the specimen of the yellowbar angelfish.

\section{REFERENCES}

Allen G.R., Steene R., Allen M. 1998. A guide to angelfishes and butterflyfishes. Odyssey Publishing/Tropical Reef Research. Perth.

Bariche M. 2010. First record of the angelfish Pomacanthus maculosus (Teleostei: Pomacanthidae) in the Mediterranean. Aqua: International Journal of Ichthyology 16 (1): 31-33.

Lieske E., Myers R.F. 2004. Coral reef guide-Red Sea to Gulf of Aden, South Oman. Harper Collins, London.

Randall J.E. 1983. Red Sea reef fishes. IMMEL publishing, London.

Randall J.E. 1995. Coastal fishes of Oman. University of Hawai'i Press, Honolulu.

Received: 9 September 2011

Accepted: 12 February 2012

Published electronically: 31 March 2012 